\title{
Schon lange vorher ausgebucht
}

Einmal mehr bewies sich der renommierte Ruf des alljährlichen Fortbildungskongresses der Zahnärztekammer SchleswigHolstein auf der Insel Sylt als Magnet: Mit 1300 Zahnärztinnen und Zahnärzten und Zahnmedizinischen Fachangestellten war die „58. Sylter Woche“ schon lange ausgebucht. Thema der diesjährigen Tagung lautete „Ein Lächeln für die Zukunft - Kinderzahnheilkunde“, das zuletzt vor genau 10 Jahren auch im Mittelpunkt der Sylter Tagung stand. Und noch ein Jubiläum konnte der Präsident der ZÄK-Schleswig - Holstein Dr. Michael Brandt bei der Eröffnung verkünden: Seit 10 Jahren gibt es bei der thematischen Gestaltung der Tagung eine Kooperation mit Fachgesellschaften. In diesem Jahr nun wieder mit derGesellschaft für Kinderzahnheilkunde. Hauptfokus der Vorträge lag auf der schwierigen Frage: „Wieviel Karies muss entfernt werden?". Vor allem bei der Milchzahntherapie ist das eine tägliche Herausforderung in der Praxis. Das Thema zog sich wie ein roter Faden durch die Woche. Prof. Sebastian Paris (Berlin): „Karies ist eine Lifestyle-Erkrankung. Nach der aktuellen ökologischen Plaquehypothese geht es in 1. Linie um Kariesmanagement mit Wiederherstellung der Reinigungsfähigkeit und Hinauszögern der 1. Restauration“ - Prof. Hendrik Meyer-Lückel (Aachen): „Kreatives Bohren“ - Prof. Norbert Krämer (Gießen): „Bei symptomlosen Zähnen keine vollständige Exkavation in Pulpennähe, wenn dicht versiegelt werden kann.“ und Prof. Ivo Krejci (Genf): „Initiale kariöse Läsionen behandeln: Füllung heißt nicht gleich bohren, sondern nicht invasive adhäsive Restauration."Dr. Andreas Sporbeck, verantwortlich für Konzeption und Durchführung, beendete die Kongresswoche und sprach den Referenten, dem Kooperationspartner Deutsche Gesellschaft für Kinderzahnheilkunde (DGKiZ) und den Teilnehmern der Sylter Woche seinen Dank aus. Er unterstrich und lobte die frequente Belegung der Vorträge und Seminare, obwohl das absolute Kaiserwetter eher in den Strandkorb einlud, und kündigte die 59. Sylter Woche an mit dem Titel „Verschlungene Pfade - Endodontie von A-Z“. Der Kongress wird auch 2017 wie immer in der Woche vor Pfingsten stattfinden. 